\title{
Study of Urban Expansion and Driving Forces Based on RS and GIS
}

\author{
----A Case Study of Tangshan City \\ Yang Zhou ${ }^{1,3}$, Huanan $\mathrm{Li}^{2}$, Chang $\mathrm{Liu}^{3}$ \\ 1 College of Resources Science and Technology, Beijing Normal University \\ Beijing 100875, China \\ 2 School of Traffic and Transportation, Beijing Jiaotong University \\ Beijing 100044, China \\ 3 Twenty First Century Aerospace Technology Co., Ltd. \\ Beijing 100096, China \\ 201131190027@mail.bnu.edu.cn
}

\begin{abstract}
In the period of rapid urbanization, timely and comprehensively understanding the spatial and temporal characteristics of urban expansion has substantial meaning for the city scientific planning and rational use of land. This paper, using the multispectral image data of "TM" and "Beijing-1" small satellite and based on geographic information system (ArcGIS) data analysis platform, carries out the statistical analysis of builtup area expansion and space variationin Tangshan City, Hebei Province in the recent 20 years from 1988 to 2009;interprets the occupied land-use types during the process of urban expansion; analyzes the impact of urban expansion on land use; extracts the urban road network and analyzes the relationship between urban expansion and road network through the establishment of buffering area and overlay analysis. On this basis, the driving forces of urban expansion are analyzed by integrating the natural condition, economic development, populationgrowth and transportation constructionplan in the Tangshan City, revealing the evolution law of Tangshan City spatial pattern and trends which shall direct the corresponding measurementfor the rational distribution of urban development in the future.
\end{abstract}

Keywords - urban expansion, remote sensing, driving forces, Tangshan City

\section{INTRODUCTION}

Nowadays, China is under the stage of rapid urbanization.To keep abreast of the historical footprint of urban expansion and its trends in future are particularly important.By understanding the coverage, conversion speed, orientation of extended urban built-up area, the relationship of land type conversion during the spatialand temporalchange progress, the law of urbanization ${ }^{[1]}$ can be revealed which could provide the foundation for scientific planning and rational distribution of modern cities' development as well as for rational land use and farmland protection.

In recent years, due to the development of remote sensing observation technology, many researches are on the dynamic change of urban expansion from different aspect.The main directions areurban expansion morphology and expansion mode ${ }^{[2-3]}$, expansion mechanism and driving forces ${ }^{[4-5]}$, urban expansion and land use ${ }^{[6-7]}$, expansion forecast models ${ }^{[8-10]}$ and so on.

Based on the "TM"and"Beijing-1"small satellite multispectral image data, this paper implements the built-up area monitoring of Tangshan City nearly two decades in fouraspects: monitoring the urban built-up area boundary of Tangshan City in 1988,1998,2008,2009; analyzing the spatialtemporalchange progress of built-up area expansion; interpreting the types of occupied land and its number and proportion in three period during the urban expansion process and analyzing the impact of urban expansion on land use; extracting urban traffic network in four levels (freeway, railway, national and provincial road) and analyzing the relationship between urban expansion and traffic network. Based on aforesaid fourresearch aspects, the driving forces of urban expansion areanalyzed in-depth to provide a foundation for city scientific planning and rational land use structure adjustment.

\section{STUDY AREA AND DATA SOURCE}

Tangshan is one of the important cities in Hebei Province, located in the northeastern part of Hebei Province at $117^{\circ} 31^{\prime}$ $119^{\circ} 19^{\prime} \mathrm{S}, 38^{\circ} 55^{\prime}-40^{\circ} 28^{\prime} \mathrm{N}$, about $130 \mathrm{~km}$ wide in west-east and $150 \mathrm{~km}$ wide in north-south. It is neighboring Bohai Sea in the south and Yanshan Mountainin the north, adjacent to Beijing and Tianjin in the west, which is an important part of the Beijing-Tianjin-Tangshan metropolitan area. The Tangshan city has six districts and six counties, and until the year of 2012 its population is about $7,417,800$ and covering 13472 square kilometers. It's a century-old coastal city of heavy industry which is located in the fortress as Beijing-Shenyang, BeijingQinhuangdao and Datong-Qinhuangdao three railways across the whole territory, linking the north and the northeast regions of China.

This paper uses 30m resolution "TM" data in 1988, 1998 and"Beijing-1" small satellite $32 \mathrm{~m}$ resolution multi-spectral remote sensing image in 2008 and 2009 to dynamically monitor the urban expansion of Tangshan.Four periods'remote 
sensing images have very good quality with cloud-free coverage. Other assistant data includes the DEM images, topographic maps, atlas and the national administrative boundary map of province, cityand county.

\section{REMOTE SENSING MONITORING AND ANALYSIS ON URBAN BUILT-UP AREA EXPANSION}

\section{A. Related Concepts}

\section{1) Built-up Area}

Urban built-up area generally refers to the actual development and construction areas centralizing the basically municipal utilities and public infrastructure. In this paper, airport is covered in the range of built-up area.

2) Type of Occupied Land in the Process of Urban Expansion

As the center of built-up areas have been expanding constantly, urban expansion's impact on the surrounding land is mainly occupying the other types of land. By using "National Land Classification (Trial)" as reference, the actual occupied land types during the urban expansion is divided into three categories, including arable land (referring to the land for cultivation of crops), construction land (referring to the urban land, rural residential land, independent mining and transport land) and other land (referring to water, woodland, grass and unused land).

\section{3) Transport Infrastructure}

Transport infrastructure contains a large number of contents. This paper focuses on extraction and monitoring of four types of infrastructure, including the freeway, railway, national road, provincial road.

\section{B. Urban Expansion Area and Spatial Variation Analysis}

From 1988 to 2008, the built-up area of Tangshan City had expanded from $83.37 \mathrm{~km}^{2}$ to $151.55 \mathrm{~km}^{2}$, and total extension area reached $68.18 \mathrm{~km}^{2}$ with expansion ratio of $81.78 \%$. In 2009 , the built-up area increased to $264.38 \mathrm{~km}^{2}$ which was three times of that in 1988 and the expansion area reached $181.01 \mathrm{~km}^{2}$ with expansion ratio as high as $217.12 \%$. It can be seen from the expansion rate that the built-up area is greatly accelerated in recent years along with the rapid development of the urban economy. According to the Tangshan City planning, in 2020, Tangshan central city area will reach more than $300 \mathrm{~km}^{2}$, which can be foreseen that the future expansion will be even faster.

The progress of built-up area expansion spatial distribution in the city center of Tangshan in past 20 years is shown in Figure 1-a. From the analysis of Figure 1-a, we can see from the late 1980 s to the late 1990 s, the Tangshan city center builtup area expansion has obviousdirection and major expansion is to the northwest, while the pace of expansion is slow in other directions. From the late 1990 s to 2008 , the built-up area expansion direction of Tangshan city center changes from northwest to the surrounding direction.From 2008 to 2009, the built-up area expansion is very fast, mainly towards the southwest, supplemented by the direction of the north and northeast, and accompaniedwith the phenomenon of the city internal blank area is filled.

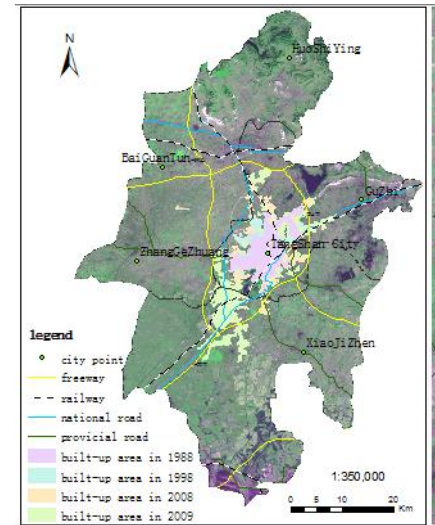

(a)

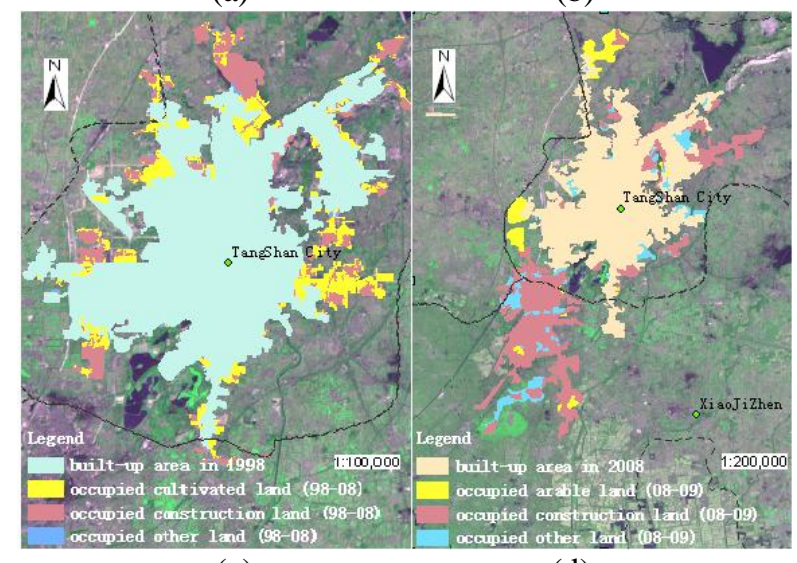

(c)

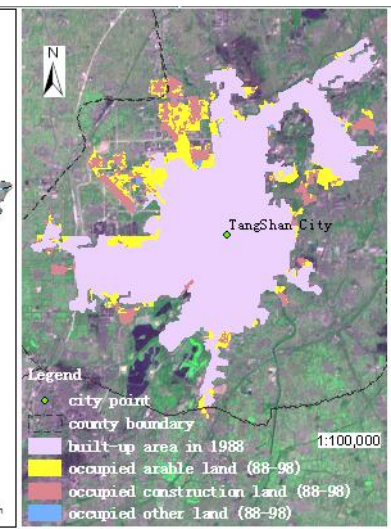

(b)

(d)
Fig. 1. Tangshan City built-up area expansion and occupied land type.

\section{The Volume of Occupied Land Type and Orientation \\ Analysis during the Process of Urban Expansion}

From 1988 to 1998, the total area of occupied land, includingarable land, construction land and other land, is $20.71 \mathrm{~km}^{2}$ during the urban expansion process. About half of the occupied landcomes from the arable land and $40 \%$ from the construction land, only about $2 \%$ from the other type of land. In this decade, Tangshan urban expansion shows significant directivity which is towards to the northwest where the most occupied arable land and construction land located (as shown in Figure 1-b).

During the period from 1998 to 2008, the area of arable, construction and other land occupied by urban expansion of Tangshan City is $47.47 \mathrm{~km}^{2}$. The occupied proportion law of the three land types is consistent with the previous period. The proportion of arable, construction and other landis about 52\%, $46 \%, 2 \%$. The basic type of occupied land is arable land which is close to the original built-up areas during the expansion. The basic occupied land during outer expansion is construction land, and the features of merging with original construction land can be found (as shown in Figure 1-c).

During the period from 2008 to 2009 , the area of arable, construction and other land occupied by urban expansion is $112.83 \mathrm{~km}^{2}$.Construction land is in an absolute dominant position whose ratio reaches $70.85 \%$, while arable land and other land are about $10 \%$ separately. It shows a significant 
feature of merging with original construction land (as shown in Figure 1-d).

In summary, urban expansion also has a certain direction by occupying land in various types.Arable land is basically from the north and west.Most of the construction land locates in both directions from the northeast and southwest.There are two main sources of other land -- the internal blank area of the original built-up area and the merged construction land of villages and towns.

\section{The Link between Urban Expansion and Major Roads}

The road infrastructure is a media between towns, and plays a very important role in urban development. The analysis of the relationship between the urban built-up area expansion direction and the main roads has significant meaning for understanding the urban built-up area development pattern.

The main roads' spatial distribution in Tangshan City is acquiredthrough monitoring. From the statistical data, total length of four major types of roads including freeway, railway, national and provincial road is $2325 \mathrm{~km}$. The distribution of roads is dispersing, and mainly of it is the provincial road, whilefreeway, railway and national road have the similar length. Spatial distribution is shown in Figure 1-a.

Road infrastructure has a certain range of radiation effects.This paper is based on the establishment of buffer zones along the main roads, to analyze the relationship between polygons of urban built-up area expanded and road radiation zones. By specifically setting the buffer size as the range of 300 meters, 500 meters and 1,000 meters, the urban expansion polygons distribution data is overplayed for analysis, carrying out the statistics of proportion relationship between different roads buffer zones and expansion polygons in Tangshan.

Through the statistical data analysis, it shows that the expansion polygons within the buffering area are increased with the expansionof radius of such buffering areain different period. From 1988 to 1998 , the corresponding proportion of expansion polygons in the $300 \mathrm{~m}, 500 \mathrm{~m}, 1,000 \mathrm{~m}$ road buffering area were $19 \%, 28 \%, 45 \%$. Inthe 21 st century, with the rapid economic development, such proportion increased greatly by about $10 \%$. In two periods from 1998 to 2008 and from 2008 to 2009 , the main roads buffer area within $1,000 \mathrm{~m}$ possessed more than $60 \%$ of new urban expansion polygons. Urban expansion shows significant characteristics in road direction along the main road, and the road infrastructure is of great importance in the pattern of urban built-up area expansion.

\section{DRIVING ForCES ANALYSIS OF URBAN SPATIAL EXPANSION}

The driving forces of urban expansion are analyzed from four aspects: population growth, economic development, transportationconstruction, natural and geographical conditions. Population growth will lead to land use incensement in spatial scale which shall inevitably promote the urban area expansion gradually. Economic development is the fundamental driving force for urban expansion, as the economy is the basic factor to determine the direction of the development. The traffic is the lifeline for urban development.Urban expansion will inevitably be towardsto the superior traffic conditions and transportation has great impact on the direction of urban built-up area expansion. In recent years, the impact of natural and geographical conditions on urban expansion is increasing day by day.There are two factors: one is the mountain of city itself formed as a natural barrier of urban expansionwhich blocks urban expansion; the other oneisthat the nature reserves, basic farmland protection area, ecological conservationand some other elements constrain urban expansion.

\section{A. Analysis of Population Growth Driving Force}

The space requirement of the growing urban population is the source for urban expansion. A direct manifestation of the population growth is demand for housings, transportation, hospitals, schools, restaurants and other basic infrastructure, which would inevitably lead to the expansion of urbanspace. This paper, based on population and built-up area statisticsof Tangshan City in the period from 1992 to 2007, obtainsa very high linear correlation with the correlation coefficient of 0.8 through correlation analysis (as shown in Figure 2). Thus, urban population growth is one of the keydriving forces of urban built-up area expansion.

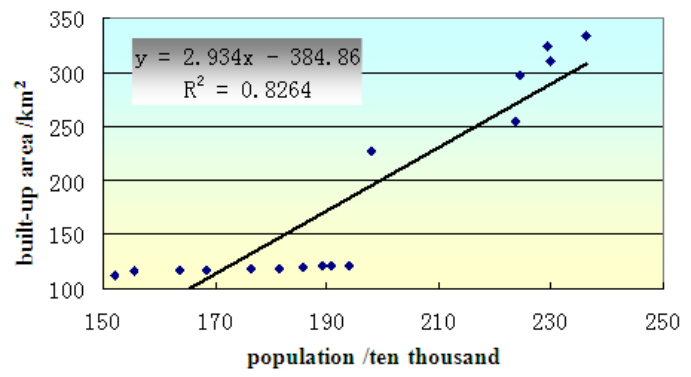

Fig. 2. Tangshan City, population and built-up area correlation.

\section{B. Driving Force of Economic Development}

Since the reform and opening, China has maintained a GDP growth rate of up to $10 \%$ per year, and the speed of economic development draws the world's attention. The economy is the basicfactor to determine the direction of development, and is the fundamental driving force of urban expansion. GDP reflects region's economic development as a comprehensive indicator.The paper, based onGDPand the built-up area statisticsof Tangshan City during 1997-2007, obtains a very high linear correlation with a correlation coefficient of 0.8 by correlation analysis (as shown in Figure 3). Thus, economic development is one of the important driving forces of urban built-up area expansion.

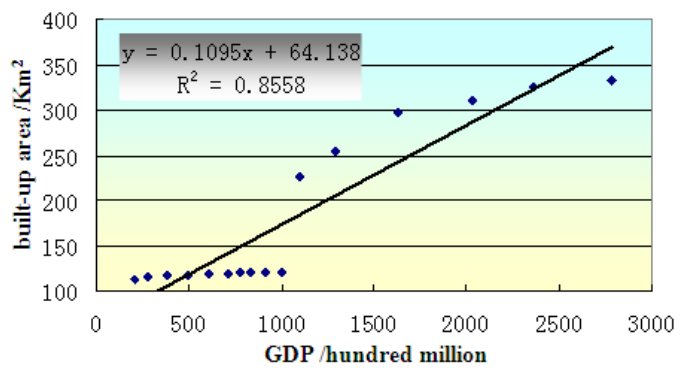

Fig. 3. Tangshan City, GDP and built-up area correlation. 


\section{Analysis of Road Traffic Driving Force}

Tangshan City is acriticaltransportation center in China, as a hubfrom north to the northeast of China.The roads together with railway and freeway connect into a network and the traffic is highly developed. Beijing-Shenyang, Beijing-Qinhuangdao and Datong-Qinhuangdao three major railwaysare across its territory.Four freeways in Tangshan city are with the total length of $288 \mathrm{~km}$ and the density of $2.12 \mathrm{~km} / 100 \mathrm{~km}^{2}$, reaching the level of developed countries in the world.

Developed road traffic has significant impact on urban expansion direction in Tangshan City. It can be seen from figure 1-athe urban expansion is towardto areas withbetter traffic conditions and higher road network density. It has the characteristics of radioactive growthalong the road network and filling up the gap between the inter-axis of road network. Itshows the road traffic has a crucial influenceon the direction of urban expansion.

\section{Natural and Geographical Conditions Constraining Factor Analysis}

The north of Tangshan City is s mountain and the south is the gulf.So the northward expansion will slow down by natural hinder of northern mountain. Due to its rich marine resources and with the construction of the Harbor Development Zone, Tangshan City will greatly acceleratethe speed of built-up area expansion in the south.

\section{CONCLUSION}

The paper, using "TM"image data in 1988 and 1998, "Beijing-1" small satellite image data in 2008 and 2009 and topographic map, through ArcGIS data processing platform, extracts the Tangshan city built-up area boundary, interprets new increased polygons within the original land use types in built-up area, extractsfreeway, railway, national and provincial road, analyzes the law of urban expansionfrom different aspects, and finally analyzes driving forces from four expects includingpopulation growth, economic development, transportation construction, natural and geographical conditions in Tangshan City.

By usingthe overlay analysis of three periods' built-up area boundary in the last two decades of the Tangshan City, it can be concluded thatthe regional expansion area of $181.01 \mathrm{~km}^{2}$ in all with the expansion ratio of $217.12 \%$, which shows that the expansion process is very fast.

Byinterpretingthe land-use types of new polygons on builtup area from the original image during 1988-2008, it showsthat the mainly occupied land use type is arable land whose proportionis about $50 \%$ and a very low unused land proportion of $2 \%$, while the other $40 \%$ is the construction land. During 2008-2009, the urban expansion occupied land is mainly focusing on the construction land, and itsratio reaches $70.83 \%$.Meanwhile, the proportion of the arable land and other land areabout $10 \%$ separately. The main form of urban expansion changestothe merging of city surrounding township.

Byestablishing $300 \mathrm{~m}, 500 \mathrm{~m}, 1,000 \mathrm{~m}$ road buffering area, based on extracting of four levelsroad network, the relationship between transportation and urban expansion isanalyzed by overlaying with new polygons. The result shows that the expansion polygons proportion increaseswhile the buffering radius is enlarging. During 1988-1998, it was 19\%, 28\%, 45\% and after entering the 21 st century, with the rapid economic development, the proportion is significantly promoted about $10 \%$. During two periods of 1998-2008 and 2008-2009, more than $60 \%$ of urban expansion new polygons are fullylocated in $1,000 \mathrm{~m}$ buffering areawithin the scope of the major roads.Urban expansion clearlyshowsthe road directivity and the characteristic of its distribution is along the main roads. Obviously, the road infrastructure expansion has a criticalimpact on the expansion pattern of urban built-up area.

Finally, through the analysis of four driving forces of urban expansion, the population growth is identified as the source power, economic development is the fundamental driving force, the road traffic and the natural and geographical factors have a significant impact on the expansion direction.

\section{REFERENCES}

[1] SHI Pei-jun, CHEN Jin, PAN Yao-zhong. Landuse Change Mechanism in Shenzhen City. Journal of Geographical Science, vol.55, pp.151-161, March 2000 (In Chinese).

[2] XU Feng, LIU Zhao-li, CHEN Jian-jun. Remote Sensing Monitor and Spatial-temporal Process' Analyses on Urban Expansion of Changchun City During Past 50 Years. Journal of Arid Land Resources and Environment, vol.19, pp.80-84, December 2005 (In Chinese).

[3] PAN Wei-hua, XU Han-qiu. A Study of Urban Spatial Expansion of Quanzhou City on the Basis of Remote Sensing Technology and Urbanization Core Analysis. Remote Sensing for Land Resources, No.4, pp.36-40, December 2004 (In Chinese).

[4] FENG Xiao-gang, LI Rui, MO Hong-wei. Study of Urban Expansion and Driving Factor Using RS and GIS----A Case Study of Xi'an City. Remote Sensing Technology and Application, vol.25, pp.202-208, April 2010 (In Chinese).

[5] HUANG Qing-xu, HE Chun-yang, SHI Pei-jun et al. Understanding Multi-Scale Urban Expansion Driving Forces: in the Case Study of Beijing. Economic Geography, vol.29, pp.714-721, May 2009 (In Chinese).

[6] FENG Shi-chao, GAO Xiao-hong, KANG Jian et al. Research on Land Use/cover Change and Urban Expansion in Xinxing City in Recent 30 Years. Arid Zone Research, vol.29, pp.129136, January 2012 (In Chinese).

[7] SHI Pei-jun, GONG Peng, LI Xiao-bing et al. Method and Practice of Land Use/Cover and Change. Beijing: Science Press, 2000 (In Chinese).

[8] XU Xin-liang, MIN Xi-bi, TIAN Zhan. Simulation and Prediction of Urban Expansion in Shanghai City based on GIS and LTM Model. China Population Resources and Environment, vol.20, pp.136-139, 2010 (In Chinese).

[9] Anthony Gar-On Yeh, LI Xia. Urban Growth Management in the Pearl River Delta: An Integrated Remote Sensing and GIS Approach. ITC Journal, No.1, pp.77-86, 1996.

[10] Prol-Ledesma R. M. , Uribe-Alcantara E. M. , Diaz-Molina O. Use of Cartographic Data and Landsat TM Images to Determine Land Use Change in the Vicinity of Mexico City. International Journal of Remote Sensing,vol.23, pp.1927-1933, 2002. 